\title{
A dynamic model of a vertical direct expansion ground heat exchanger
}

\author{
B. Beauchamp ${ }^{1}$, L. Lamarche ${ }^{1}$ and S. Kaj $1^{1}$ \\ ${ }^{1}$ Department of mechanical engineering \\ École de technologie supérieure \\ 1100 Notre-Dame Ouest, Montréal, (Quebec), CANADA, H3C 1K3 \\ Phone/Fax number: 1 514-396-8800/ 1514 396-8530, e-mail: benoit.beauchamp@etsmtl.ca
}

\begin{abstract}
.
The paper presents a general distributed model of a vertical U-tube direct expansion heat exchanger coupled with the ground. This model is developed for studying the dynamic thermal behavior of a buried heat exchanger (the evaporator or condenser) which is an integral part of the so-called direct expansion heat pump. The transient conservative equations of mass and energy considering the two-phase flow of refrigerant are derived and presented. The heat exchange with the ground is treated using an analytical approach to treat short time response of vertical boreholes based on an imposed heat flux. The thermal interference between the two pipes of the heat exchanger is also considered. The mathematical equations of the model are numerically presented using a finite difference scheme and the solution of the system of equations is obtained using a built-in iterative solver function of MatLab®. The dynamic behavior of a condenser and an evaporator are first obtained by imposing a change of the inlet conditions. Experimental data from a test rig are used to demonstrate the validity of the dynamic model.
\end{abstract}

\section{Key words}

Ground heat exchanger, Direct expansion, Ground source heat pump, Simulation, Dynamic.

\section{1) Introduction}

Simulation is a widely used technique for design and performance prediction purposes of refrigeration systems. Several models of ground source heat pump using a secondary loop in the ground have been developed and studied by several researchers. Most of the models of ground source heat pumps do not directly couple the refrigeration circuit (through the condenser or evaporator) with the ground heat exchange since the

ground heat exchanger is not an integral part of this circuit. Direct expansion ground source heat pumps, on the other hand, have the ground heat exchanger as an integral component of the refrigeration circuit. Therefore, simulation models of those systems must incorporate a direct coupling of heat exchange between the buried heat exchanger and the ground. In this paper, a dynamic model of a vertical direct expansion heat exchanger is presented.

\section{2) Theoretical analysis of the heat exchanger}

Figure 1 shows the conceptual model of a control volume of a vertical U-tube heat exchanger. The following assumptions are made to simplify the complexity of the two-phase flow, the thermal interference between the pipes and the thermal response of the borehole and the ground:

a) The refrigerant flow is simplified as a onedimensional homogenous flow.

b) Refrigerant pressure drops along the pipes are neglected.

c) The two phases of the refrigerant flow are assumed to be in thermal equilibrium

d) Axial conduction in the refrigerant is negligible.

e) Thermal resistance of the pipe wall is neglected.

f) For each control volume, the pipe wall temperature is considered uniform

g) For each control volume, the borehole temperature is considered uniform

h) The undisturbed ground temperature is considered axially constant 


\begin{tabular}{|c|c|c|c|}
\hline \multicolumn{4}{|c|}{ Nomenclature } \\
\hline & & $\mathrm{D}$ & Diameter (m) \\
\hline $\mathrm{T}$ & Temperature $\left({ }^{\circ} \mathrm{C}\right)$ & $\mathrm{q}$ & Heat transfer $\left(\mathrm{W} \mathrm{m}^{-3}\right.$ or $\left.\mathrm{W} \mathrm{m}^{-2}\right)$ \\
\hline$\rho$ & Density $\left(\mathrm{kg} \mathrm{m}^{-3}\right)$ & $\mathrm{R}$ & Thermal resistance $\left(\mathrm{K} \mathrm{W}^{-1}\right)$ \\
\hline & Velocity $\left(\mathrm{m} \mathrm{s}^{-1}\right)$ & \multirow{2}{*}{\multicolumn{2}{|c|}{ Lower indices }} \\
\hline $\mathrm{x}$ & Position (m) & & \\
\hline $\mathrm{h}$ & Enthalpy $\left(\mathrm{J} \mathrm{kg}^{-1}\right)$ & $\mathrm{hx}$ & Pipe wall \\
\hline $\mathrm{t}$ & Time $(s)$ & ${ }^{111}$ & Refrigerant \\
\hline A & Pipe cross section $\left(\mathrm{m}^{2}\right)$ & $\begin{array}{l}\mathrm{R} \\
\mathrm{B}\end{array}$ & Borehole \\
\hline V & Volume $\left(\mathrm{m}^{3}\right)$ & B & Reference \\
\hline $\mathrm{P}$ & Pressure $(\mathrm{Pa})$ & $\mathrm{i}$ & Inlet \\
\hline $\mathrm{m}$ & Mass flow rate $\left(\mathrm{kg} \mathrm{s}^{-1}\right)$ & & Upstream \\
\hline $\mathrm{Cp}$ & Specific heat $\left(\mathrm{J} \mathrm{kg}^{-1} \mathrm{~K}^{-1}\right)$ & $\begin{array}{l}\mathrm{U} \\
\mathrm{D}\end{array}$ & Donwstream \\
\hline $\mathrm{H}$ & Heat transfer coefficient $\left(\mathrm{W} \mathrm{m}{ }^{-2} \mathrm{~K}^{-1}\right)$ & $\begin{array}{l}\mathrm{D} \\
\mathrm{G}\end{array}$ & Ground \\
\hline
\end{tabular}

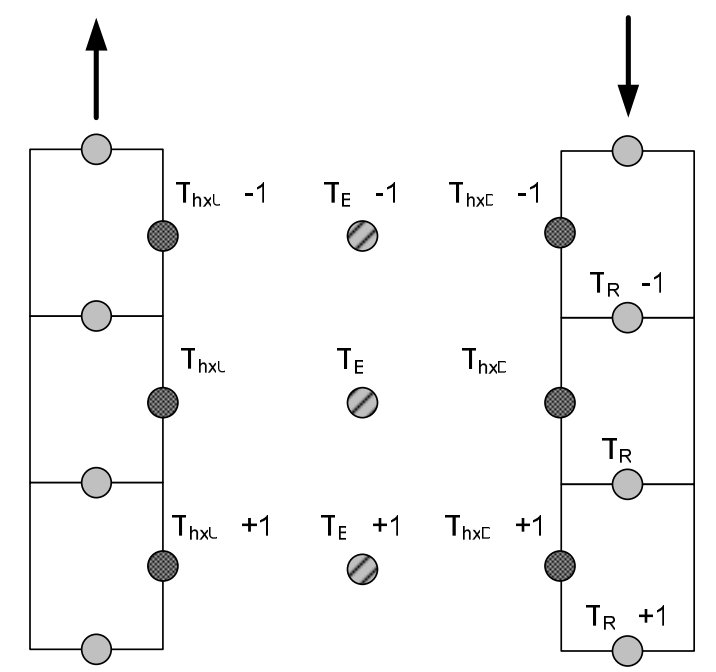

Fig. 1. Conceptual model of a control volume

\section{A. Refrigerant flow in the pipe}

Based on the above assumptions, the conservative equations for mass and energy can be expressed as follow [1]:

$$
\begin{gathered}
\frac{\partial \rho}{\partial t}+\frac{\partial(\rho w)}{\partial x}=0 \\
\frac{\partial\left(\rho h+1 / 2 \rho w^{2}-P\right)}{\partial t}+\frac{\partial\left(1 / 2 \rho w^{3}+\rho w h\right)}{\partial x}-q_{R}=0
\end{gathered}
$$

For simulation purposes, they are expressed in term of the mass flow rate:

$$
\frac{\partial \rho A}{\partial t}+\frac{\partial m}{\partial x}=0
$$

$$
\frac{\partial\left(\rho h+\frac{1 / 2 m^{2}}{\rho^{2} A^{2}}-P\right)}{\partial t}+\frac{\partial\left(\frac{1 / 2 m^{3}}{\rho^{2} A^{3}}+\frac{m h}{A}\right)}{\partial x}-q_{R}=0 \text { (4) }
$$

Where the refrigerant side heat transfer is expressed as:

$$
q_{R}=4 H_{R} D_{i_{R}}^{-1}\left(T_{R}-T_{h x}\right)
$$

Where $T_{R}$ is the control volume averaged refrigerant temperature and $\mathrm{H}_{\mathrm{R}}$ is the refrigerant heat transfer coefficient.

The above equations are valid for both the condenser and the evaporator refrigerant flow undergoing any state change (gas, liquid or two-phase flow). The evaluation of the heat transfer coefficient is dependant of the phase flow and is treated separately.

The refrigerant thermodynamic properties are evaluated locally using predefined polynomial equations based on NIST REFPROP 7.0 results from equations of state. This method greatly improves the calculation speed of refrigerant thermal properties.

\section{B. Heat conduction in the pipe wall}

For each control volume, the pipe wall temperature is considered uniform. Neglecting the metallic pipe wall thermal resistance but considering its capacitance, the pipe wall energy balance is written in the following form:

$$
\rho V C_{p} \partial \frac{T_{h x}}{\partial t}-q_{R}+q_{B}=0
$$

Where the refrigerant side heat transfer $\left(q_{R}\right)$ is as described above and the borehole side heat transfer $\left(q_{B}\right)$ is expressed as: 


$$
q_{B}=\frac{\left(T_{h x D}-T_{B}\right)}{R_{1}^{\Delta}}+\frac{\left(T_{h x D}-T_{h x U}\right)}{R_{12}^{\Delta}}
$$

The expression for $R_{1}^{\Delta}$ and $R_{12}^{\Delta}$ are described in [2] and presented in Figure 2. Those resistances and their respective thermal circuit are used to describe the local heat flow between the U-tube and the borehole wall. The resistances are evaluated considering two identical pipes placed in a symmetric position and diametrically opposed with respect to the centre of the boreholes.

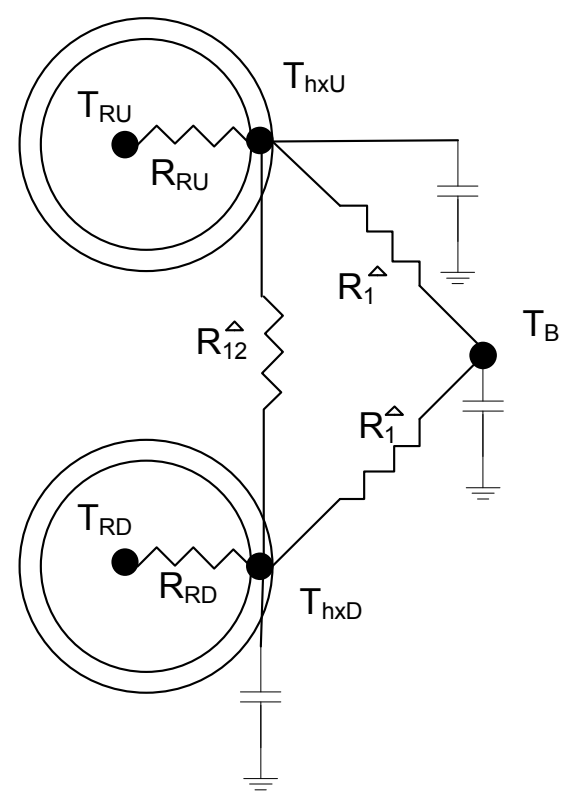

Fig. 2. Thermal resistances of a cross-section of the heat exchanger

\section{3) Theoretical analysis of ground heat exchange}

Simulating transient performance of refrigeration systems is usually done using relatively short time step in the order of seconds or minutes. Therefore, in the model presented, the appropriate modeling of the thermal ground response must be done in accordance with this short-time analysis. Most of the analytical models (using whether a cylindrical heat source or a line source method) developed for the thermal response of the ground are valid after few hours of operation because they neglect the heat capacity of the borehole. The model presented in this paper uses the cylindrical heat source approach and is valuable since the pipe wall and the borehole thermal capacitance are considered in the numerical solution of the problem. Therefore, when a heat flow is imposed between the fluid and the ground, it is not immediately felt by the ground because of the presence of above thermal capacitances.

The borehole energy balance, including its heat capacity is expressed as:

$$
\rho V C_{p} \partial \frac{T_{B}}{\partial t}-q_{B}+q_{G}=0
$$

Therefore, it is possible to express the ground heat transfer as:

$$
q_{G}=q_{B}-\rho V C_{p} \partial \frac{T_{B}}{\partial t}
$$

The thermal response of the borehole $\left(T_{B}\right)$ is obtained using the well-known approach of the cylindrical heat source. In order to improve computational speed, a recently proposed nonhistory-dependent scheme [3] is used instead of the classical convolution scheme expressed as follow:

$$
T_{B}=T_{G}+\sum_{i=1}^{N} \frac{q_{G, j}-q_{G, j-1}}{k_{G}} G_{q}\left(1, t-t_{j-1}\right)
$$

Where $G_{q}$ is the G-function for imposed fixed flux.

\section{4) Numerical solution of the model}

The equations are presented in a dimensionless form to improve the rate of convergence. The resulting heat and mass conservation equations of the refrigerant flow are presented below. The dimensionless form of equation (4) is obtained similarly.

$$
\begin{gathered}
\frac{\partial \rho / \rho_{r e f}}{\partial t^{*}}+\frac{\partial m / m_{r e f}}{\partial x^{*}}=0 \\
t^{*}=t\left(w_{r e f} / L_{r e f}\right) \\
x^{*}=x / L_{r e f} \\
\frac{\partial E_{t}^{*}}{\partial t^{*}}+\frac{\partial E_{s}^{*}}{\partial x^{*}}-q_{R}^{*}=0 \\
E_{t}^{*}=\left(\frac{\rho h+\frac{1}{2} m^{2}}{\rho^{2} A^{2}}-P\right) /\left(\rho_{r e f} h_{r e f}\right) \\
E_{t}^{*}=\left(\frac{1 / 2 m^{3}}{\rho^{2} A^{3}}+\frac{m h}{A}\right) /\left(m_{r e f} h_{r e f} / A_{r e f}\right) \\
q_{R}^{*}=q_{R}\left(\frac{A_{r e f} L_{r e f}}{m_{r e f} h_{r e f}}\right)
\end{gathered}
$$

The model solves a transient, dimensional problem; all parameters vary with space and time. The governing equations are discretized to algebraic equations using a purely implicit finite difference scheme [1]. The solution of the system of discretized nonlinear equations is obtained using a built-in iterative solver function of MatLab®. Based on the numerical approach proposed, the solution of the dependent variables (refrigerant mass 
flow rate, refrigerant enthalpy, and pipe wall temperature) is obtained using a node-by-node system solution along the heat exchanger for a given time. Once the solution for all nodes of the heat exchanger is obtained for a given time, the solution for the next time step is computed.

One of the particularities of the U-tube heat exchanger is the transient thermal interference between the pipes (Fig. 1 and Fig. 2). This interference is treated in the numerical solution of the model by using the temperature of adjacent nodes in a vertical layer at the previous time step. The same treatment applies for the borehole temperature which is evaluated for a given time using the temperature of the downstream pipe at the current time step and the temperature of the upstream pipe at the previous time step. This approach simplifies the problem since the solution can be marched in space for each node along the heat exchanger for a given time and doesn't require a spatially iterative approach.

\section{5) Laboratory measurement}

A comparison of model results with experimental data is realized with a test rig. The set-up consists of a fully instrumented Nordic $®$ DXW-45 ground source heat pump installed in the laboratories of the university. The heat pump is instrumented with four (4) refrigerant pressure transducers and thirteen (13) refrigerant temperature transducers. The heat pump is connected to three vertical direct expansion ground heat exchangers of $30 \mathrm{~m}$. depth. Each heat exchanger consists of a U-tube copper pipe including one $12.7 \mathrm{~mm}$ and one $9.5 \mathrm{~mm}$ outside diameter tube. When the heat exchanger is used as a condenser, the entrance and return pipe are respectively the 9.5 and $12.7 \mathrm{~mm}$ pipes. The opposite is valuable when the heat exchanger is used as an evaporator. Five (5) thermocouples are installed on each heat exchanger pipe buried in the ground. The thermocouples are located at the inlet, the bottom and the exit of each U-tube and at depths (both pipes) of 6, 18 and 24 meters respectively for heat exchanger \#1, \#2 and \#3.

When the heat pump is at rest for a sufficiently long period, the reading of thermocouples buried in the ground for each heat exchanger represents the axially undisturbed ground temperature. For the experimental test data collected, the ground temperature measurements varied with depth between $13.2^{\circ} \mathrm{C}$ and $16.7^{\circ} \mathrm{C}$.

To collect appropriate experimental data for comparison with simulation results, the heat pump was started from rest after a sufficiently long period between each operating mode (ground heat extraction or ground heat rejection). All measured parameters were recorded at five (5) seconds interval. Figures 5 and 6 show the experimental data collected to validate and compare simulation results. The refrigerant mass flow rate was evaluated but considered constant for simulation purposes. The heat pump activates simultaneously the three ground loops when it extracts heat from the ground but activates only one loop when it rejects heat to the ground. Therefore, the refrigerant mass flow rate was set to $0.05 \mathrm{~kg} / \mathrm{s}$ for the condenser mode and $0.017 \mathrm{~kg} / \mathrm{s}$ for the evaporator mode.

\section{6) Simulation results}

Simulations for both condenser and evaporator mode were performed. The initial parameters such as refrigerant pressure, refrigerant enthalpy and pipe wall temperature are assumed based on experimental undisturbed conditions. The time-dependence of those variables can be illustrated with predefined simple mathematical functions or based on experimental data collected.

\section{A. Simulation results from inlet flow disturbances}

Simulations have been performed to demonstrate the effect of the pipe thermal interference. Based on undisturbed initial condition, the inlet variables (refrigerant mass flow rate, refrigerant enthalpy, and refrigerant pressure) are defined as a function of time. The following results present the thermal behavior of a condenser and an evaporator under the influence of a pressure time-dependent variable. All other inlet variables remain constant. The mathematical function used to define the time behavior of the pressure is of the exponential type:

$$
P(t)=P_{\text {initial }} \pm \Delta P\left(1-e^{t \tau}\right)
$$

Temperature profiles for the refrigerant and the pipe wall predicted by the model of the evaporator are shown in figure 3 for two different simulation times. The temperature profile of simulation time $250 \mathrm{~s}$. shows the refrigerant undergoes a two-phase to single phase vapor transition at $\approx 75 \%$ of the heat exchanger length. The temperature profile of simulation time 1500 s. shows refrigerant undergoes a two-phase to single phase vapor transition at $\approx 40 \%$ of the heat exchanger length. Furthermore, for this simulation time, the pipe thermal interference is clearly seen in the upstream pipe where the pipe wall temperature drops below the refrigerant temperature causing a decrease in the refrigerant superheat.

Temperature profiles for the refrigerant and the pipe wall predicted by the condenser model are shown in figure 4 for two different simulation times. The temperature profile of simulation time $20 \mathrm{~s}$. shows the refrigerant undergoes a single phase vapor to two-phase and a twophase to single phase liquid transition at $\approx 5 \%$ and $\approx 50 \%$ of the heat exchanger length respectively. The temperature profile of simulation time $300 \mathrm{~s}$. shows the refrigerant undergoes a single phase vapor to two-phase and a two-phase to single phase liquid transition at $\approx 5 \%$ and $\approx 35 \%$ of the heat exchanger length respectively. Furthermore the pipe thermal interference is clearly seen in the upstream pipe where the pipe wall temperature raises above the refrigerant temperature causing a decrease in the refrigerant subcooling. 


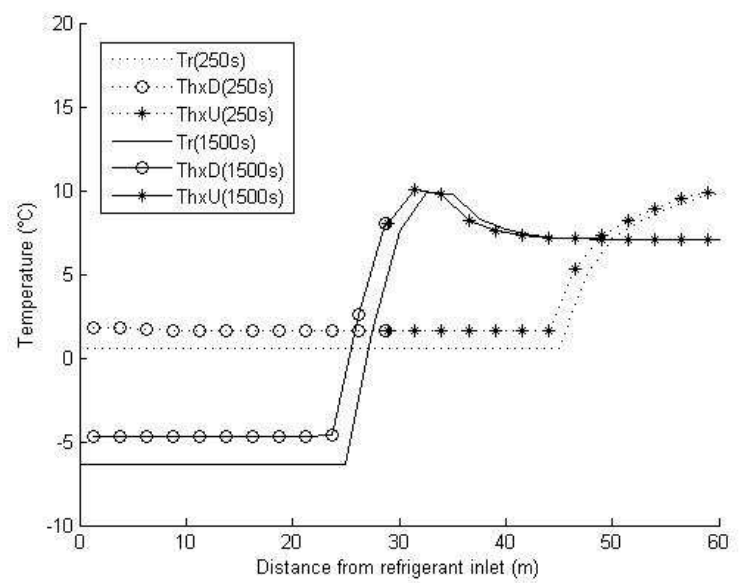

Fig. 3. Evaporator refrigerant and pipe wall temperature profile (simulation results)

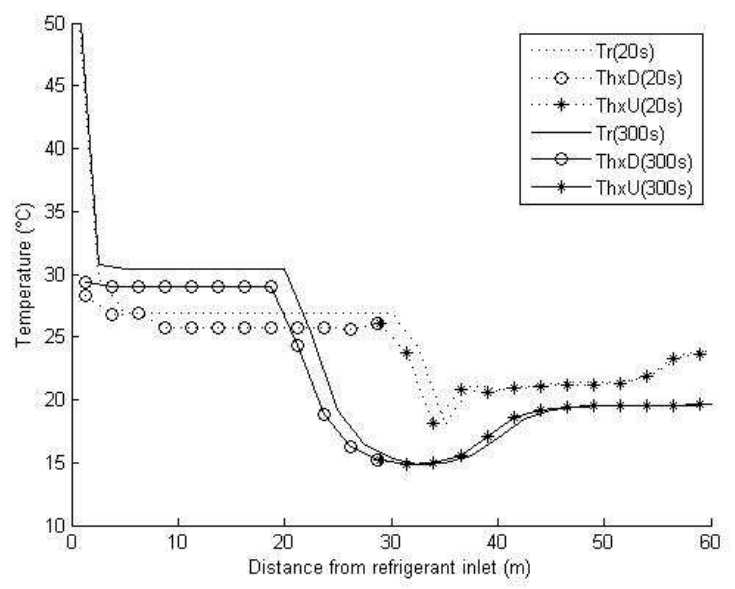

Fig. 4. Condenser refrigerant and pipe wall temperature profile (simulation results)

\section{B. Comparison of simulation results with experimental} data

From the experimental data presented in figure 5 and figure 6 , simulations have been performed. The evaporator cycling pressure and temperature oscillations in figure 6 represent the heat pump thermostatic expansion valve cycling rate. To obtain the simulation results, the model refrigerant inlet transient variables (mass flow rate, enthalpy and pressure) were imposed based on experimental measurement.

Figure 7 illustrates the similarities between the model transient refrigerant outlet temperature prediction and the experimental laboratory measurement. The discrepancies between laboratory and model values demonstrate the sensitivity of the dynamic thermal and fluid behavior of the heat exchanger to simplifying assumptions (ex: neglecting pressure drops, assuming an undisturbed uniform ground temperature, etc.) and formerly unknown parameters (ground thermal properties, groundwater movement, etc.).
Figures 8 and 9 present predicted and laboratory measured pipe wall spatial temperature profiles of the evaporator for a given time. The models results show good agreement with the experimental data for the refrigerant temperature distribution along the heat exchanger; the evaporator amount and position of superheat being clearly identified and the refrigerant temperature variation between the inlet and outlet being similar. Those results are promising for a whole system simulation since the refrigerant superheat is an important control parameter of a heat pump and the ground heat transfer (obtained from the state change of the refrigerant) is a challenging phenomenon to analyze for short and long time simulations.

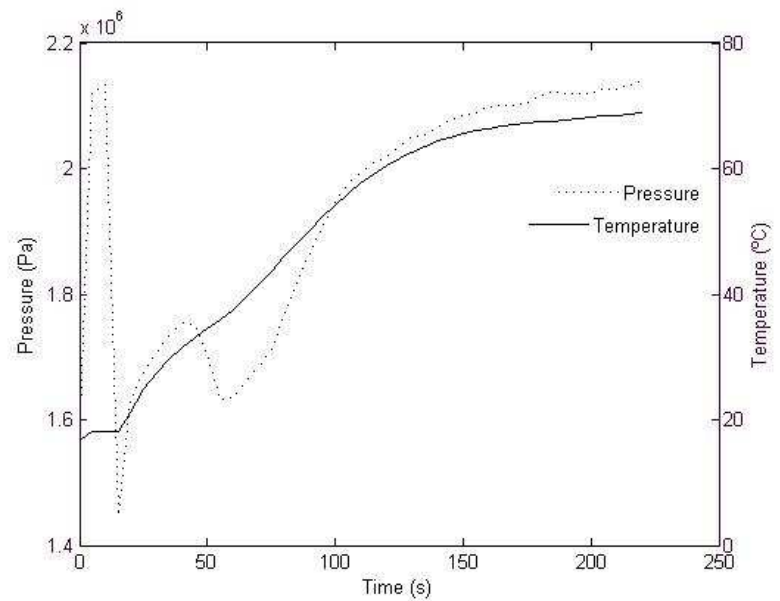

Fig. 5. Condenser experimental pressure and temperature refrigerant inlet data

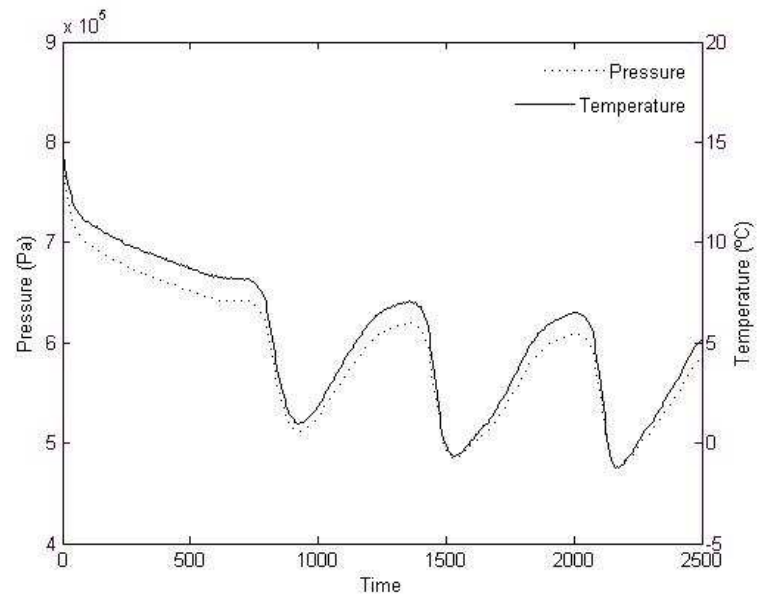

Fig. 6. Evaporator experimental pressure and temperature refrigerant inlet data 


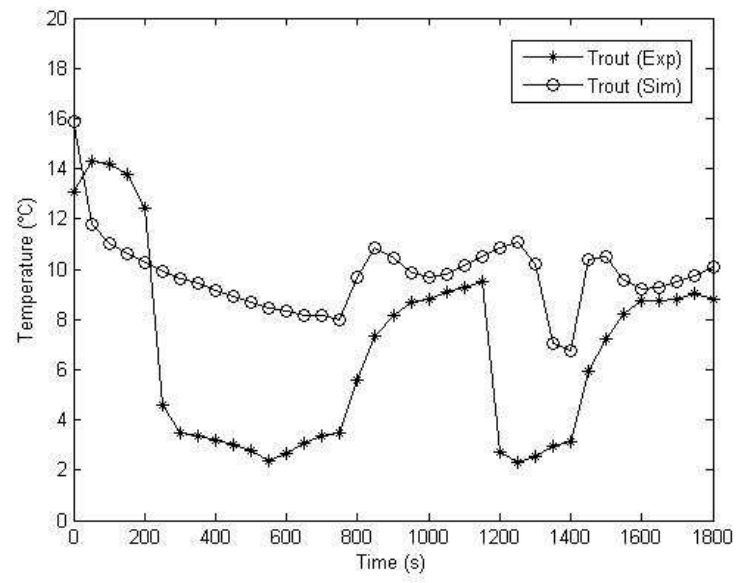

Fig. 7. Evaporator outlet refrigerant temperature (experimental and simulation results)

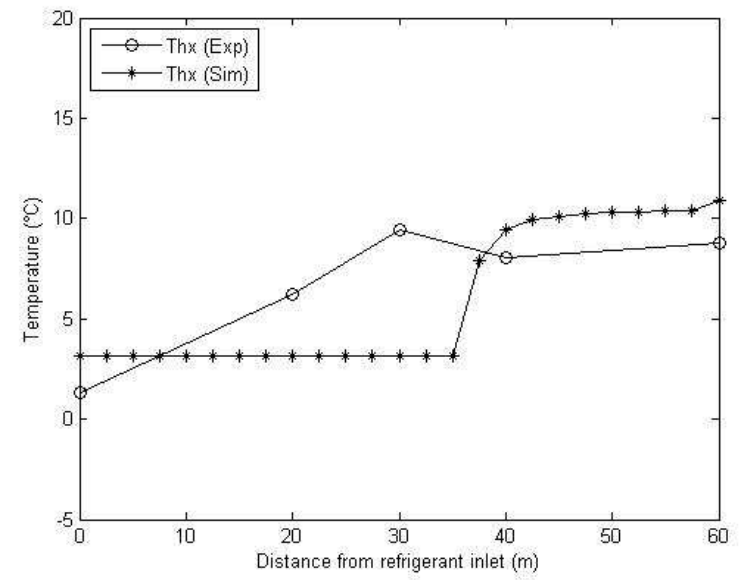

Fig. 8. Evaporator pipe wall temperature distribution after $90 \mathrm{~s}$. (experimental and simulation results).

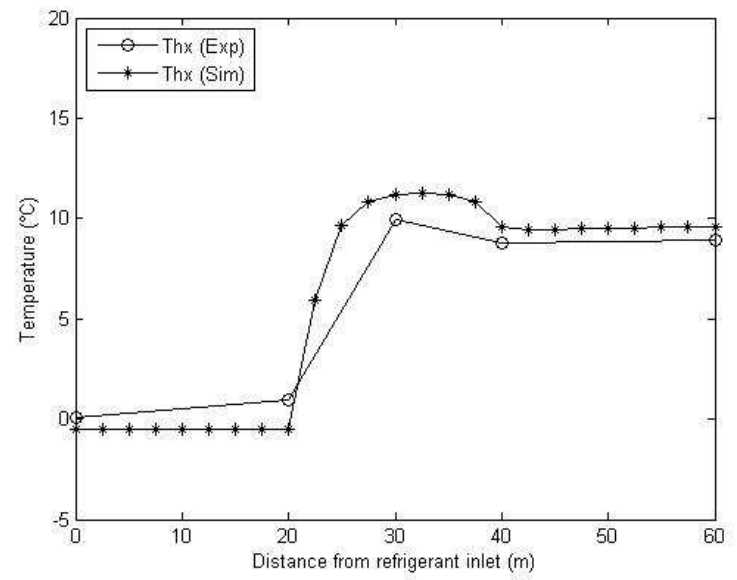

Fig. 9. Evaporator pipe wall temperature distribution after $160 \mathrm{~s}$. (experimental and simulation results)

Figure 10 illustrates the similarities between the condenser model transient refrigerant outlet temperature prediction and the experimental laboratory measurement. To obtain the simulation results, the model refrigerant inlet transient variables (mass flow rate, enthalpy and pressure) were imposed based on experimental measurement.

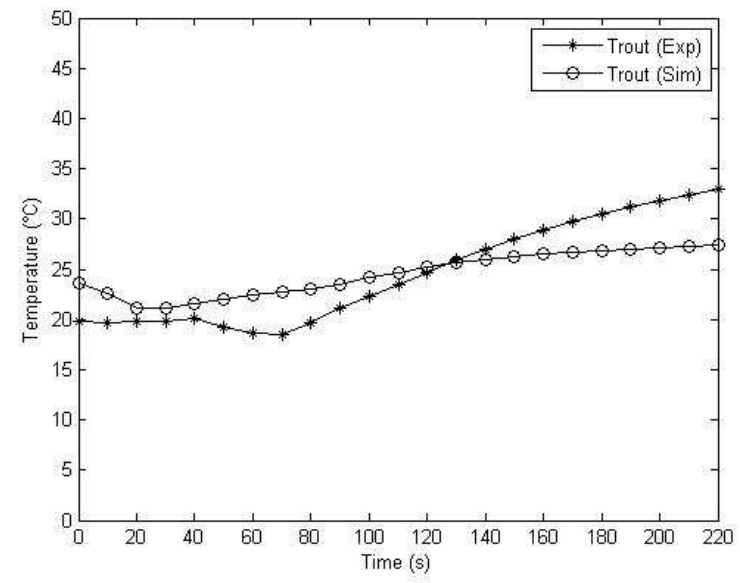

Fig. 10. Condenser outlet refrigerant temperature (experimental and simulation results)

Figures 11 and 12 present predicted and laboratory measured pipe wall spatial temperature profiles of the condenser for a given time. The models results show good agreement with the experimental data; the condenser amount and position of subcooling being clearly identified.

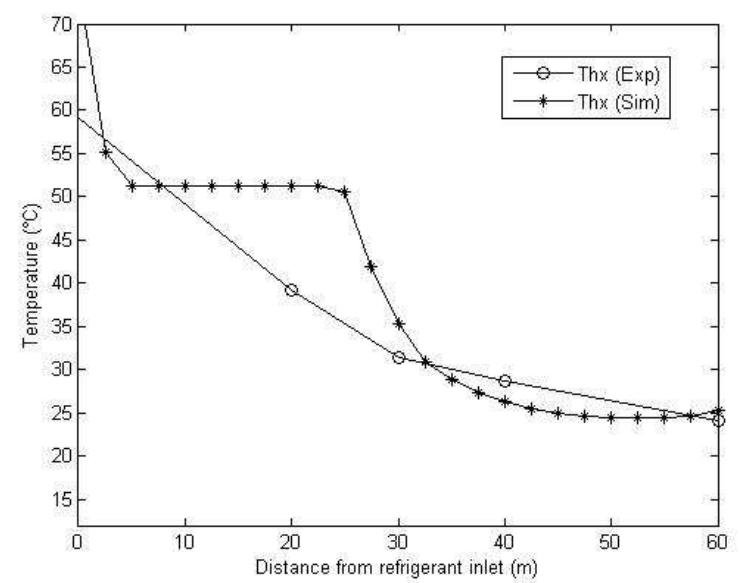

Fig. 11. Condenser pipe wall temperature distribution after $60 \mathrm{~s}$. (experimental and simulation results)

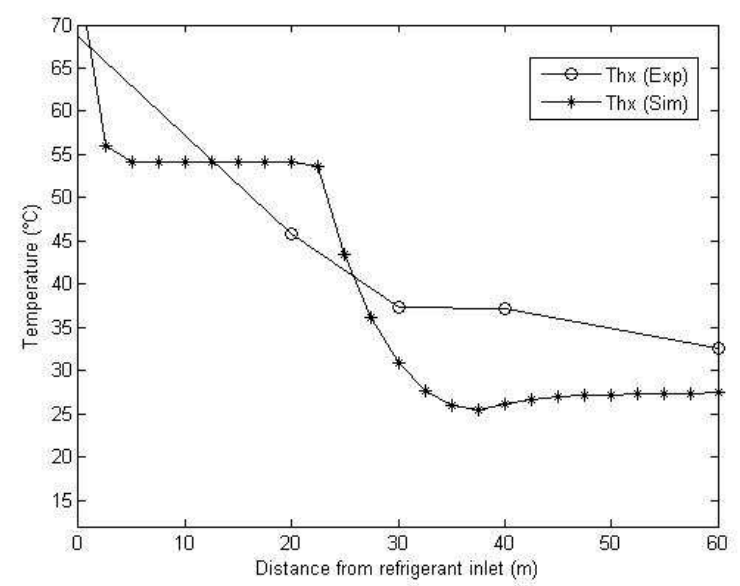

Fig. 12. Condenser pipe wall temperature distribution after $120 \mathrm{~s}$. (experimental and simulation results) 


\section{7) Conclusion}

A spatially distributed model for a vertical direct expansion ground heat exchanger has been presented. The main particularity of this model is the direct coupling of the transient ground heat exchange with the dynamics of refrigerant flow and the treatment of thermal interference of adjacent pipes. Furthermore, the spatially distributed model allows visualizing the displacement of the two-phase interface in time. More work is needed in the validation of the model parameters (heat transfer coefficients for vertical two-phase flow, influence of pressure drops, ground heat transfer properties...) in order to have more reliable models of vertical heat exchangers. Reducing computing time is an important challenge of simulation. More work is needed in the development and application of iteration procedure for the numeric solution of such models.

\section{References}

[1] J. Nyers, G. Stoyan, A dynamical model adequate for the evaporator of a heat pump. International Journal of refrigeration, Vol. 17, No. 2, pp 101-108, 1994.

[2] G. Hellstrom, Ground Heat Storage. Thermal Analysis of Duct Storage Systems. Part I Theory, Ph.D. thesis, University of Lund, Department of Mathematical Physics, Sweden, 1991.

[3] L. Lamarche, B. Beauchamp, A Fast Algorithm for the Simulation of GCHP Systems. ASHRAE

Transactions, Vol 113, No. 1, Paper DA-07-050, 2007

[4] F.Q. Wang et al., A novel special distributed method for dynamics refrigeration system simulation. International Journal of refrigeration, pp 1-17, 2006. 